\title{
Dynamic Voltage Restorer for Sag and Swell Issues in Power System
}

\author{
S. V. R. Lakshmi Kumari, M. Uma Vani \\ Dept of EEE, V.R. Siddhartha Engineering College, Vijayawada, A.P, India \\ Department of EEE, LBRCE, Mylavaram, AP, India
}

\begin{tabular}{l} 
Article Info \\
\hline Article history: \\
Received Nov 28, 2017 \\
Revised Jan 9, 2018 \\
Accepted Jan 19, 2018 \\
\hline
\end{tabular}

\section{Keywords:}

DVR

Power quality

Sag

Swell

Voltage

\begin{abstract}
This paper presents the application of dynamic voltage restorers (DVR) on power distribution Systems for mitigation of voltage sags/swells at critical loads. DVR is one of the compensating types of custom power devices. The power quality is affected mainly due to the sensitive loads which results in voltage sag and voltage swells. It is necessary to investigate the suitable methods for mitigation of voltage sags. Sensitivity is the main cause of the above power quality problems and it cannot be eliminated completely as it has many other operating properties. So the next possible solution is to correct the problems caused by the sensitive equipments connected to the faulty loads. The occurrence of sag and swell varies with equipment, environment, process operations, desired control schemes etc. From the wide range of mitigation methods, the selected one has to be observed for the effect on the characteristics. These problems can be mitigated with voltage injection method using custom power device, Dynamic Voltage Restorer (DVR). In this paper we design a Dynamic Voltage Restorer (DVR) which is utilized for power quality improvement. The main power quality problems like voltage sag and swell are studied in this paper. The device used to phase out voltage sags and a swell in the distribution lines is the Dynamic Voltage Restorer (DVR). The Dynamic Voltage Restorer is a special type of power device used for providing consistent and reliable supply power to the load devices. Dynamic Voltage Restorer uses a vector control strategy for mitigating power quality problems by automatically detecting and injecting the voltage components through an injection transformer. Here comes the importance of soft computing techniques like PI controller. The system will be able to correct repeated occurrences of the power quality problems.
\end{abstract}

Copyright $\odot 2018$ Institute of Advanced Engineering and Science. All rights reserved.

\section{Corresponding Author:}

S. V. R. Lakshmi Kumari,

Dept of EEE, V.R. Siddhartha Engineering College,

Vijayawada, A.P, India.

Email: lakshmikumari1.eee@gmail.com

\section{INTRODUCTION}

Power quality is of great importance in all modern environments where electricity is involved, power quality can be essentially influenced by an important factor like quality service. One of the major concerns in electricity industry today is power quality problems [1-3]. Presently, most of the power quality problems are due to different fault conditions. These conditions cause voltage sag, voltage swell, transients, voltage interruption and harmonics [4-5]. These problems may cause the apparatus tripping, shutdown commercial, domestic and industrial equipment, and miss process of drive system. Power distribution systems, ideally, should provide their customers with an uninterrupted flow of energy at smooth sinusoidal voltage at the contracted magnitude level and frequency however, in practice, power systems, especially the distribution systems, have numerous nonlinear loads, which significantly affect the quality of power supplies. 
As a result of the nonlinear loads, the purity of the waveform of supplies is lost. This ends up producing many power quality problems. Apart from nonlinear loads, some system events, both usual (e.g. capacitor switching, motor starling) and unusual (e.g. faults) could also inflict power quality problems [6-7]. A power quality problem is defined as any Manifested problem in voltage/current leading to frequency deviations that result in failure or disoperation of customer equipment. Power quality problems are associated with an extensive number of electromagnetic phenomena in power systems with broad ranges of time frames such as long duration variations, short duration variations and other disturbances [8-9].

Dynamic Voltage Restorer (DVR) can provide the lucrative solution to mitigate voltage sag [10-11] by establishing the appropriate voltage quality level, necessary. It is recently being used as the active solution for mitigation of power quality problems. The DVR is one of the custom power devices which can improve power quality, especially, voltage sags and voltage swells. As there are more and more concerns for the quality of supply as a result of more sensitive loads in the system conditions better understanding of the devices for mitigating power quality problems [12-13] is important.

\section{DYNAMIC VOLTAGE RESTORER (DVR)}

The Dynamic Voltage Restorer (DVR) is a series connected device analogous to a SSSC. The main function of a DVR is to eliminate or reduce voltage sags seen by sensitive loads such as semiconductor manufacturing plant or IT industry. DVR that have been installed so far are modular with ratings of 2 MVA per module. They have been designed to compensate three phase voltage sags up to $35 \%$ for duration of time less than half a second (depending on the requirement). If the voltage sag occurs only in one phase (caused by SLG faults) then the DVR may be designed to provide compensation for sags exceeding 50\%. The energy storage required in capacitors is typically in the range of 0.2 to $0.4 \mathrm{MJ}$ per MW of load served. A DVR is connected in series with the feeder using a transformer. The low voltage winding is connected to the converter. If the objective of a DVR is mainly to regulate the voltage at the load bus, it remains for most of the time in stand-by mode during which the converter is bypassed (no voltage is injected). Only when sag is detected, the DVR injects a series voltage of the required magnitude. It is necessary to protect a DVR against the fault currents (as in the case of a SSSC). A DVR with IGBT/IGCT devices can be controlled to act as a series active filter to isolate the load from voltage harmonics on the source side. It is also possible to balance the voltage on the load side by injecting negative and/or zero sequence voltages in addition to harmonic voltages, Figure 1 shows DVR block diagram.

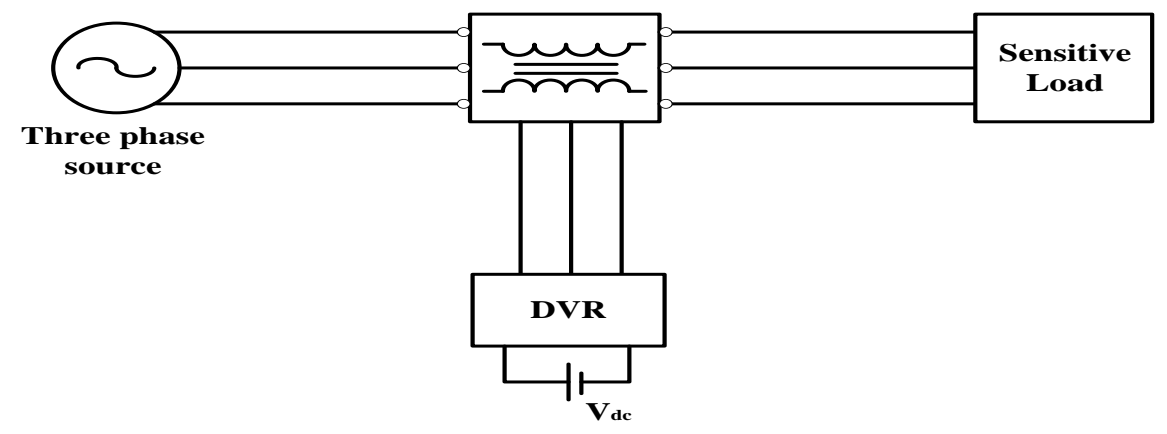

Figure 1. DVR block diagram

It is also known as a static voltage booster (SVB) or a static series compensator (SSC). It is generally installed in distribution systems. It is a series custom power device intended to protect the sensitive loads at the Point of Common Coupling (PCC) from various power quality problems. DVR has the capability to deal with line voltage harmonics, reduction of transients in voltage, fault current limitations, voltage sags, and voltage swells. Problems facing industries regarding the power quality are mainly voltage sags and swells.

DVR injects dynamically controlled voltages in series with the bus voltage through the booster transformer. The amplitudes of the injected phase voltages are controlled so as to eliminate the detrimental effects of a bus fault to the load voltage. The system impedance Zth depends on the fault level of the load bus. When the system voltage (Vth) drops, the DVR injects a series voltage VDVR through the injection 
transformer so that the desired load voltage magnitude VL can be maintained. The series injected voltage of the DVR can be written as:

$$
\begin{aligned}
& V_{D V R}=V_{L}+Z_{t h} I_{L}-V_{t h} \\
& I_{L}=\left(\frac{P_{L}+j Q_{L}}{V_{L}}\right)
\end{aligned}
$$

Where $: V_{L}$-Desired load voltage magnitude

$Z_{\text {th }}$-Load impedance

$I_{L}$-Load current

$V_{t h}$-System voltage during fault condition

\section{CONTROL TECHNIQUE FOR DVR}

\subsection{Synchronous Reference Frame (SRF) Theory}

Figure 2 shows the control block of the DVR proposed in synchronous reference frame theory which is used for the control of self supported DVR. The voltage at PCC is converted to rotating reference frame using abc-dqo conversion. Using low pass filter (LPF) harmonics and oscillatory components of voltage are eliminated.

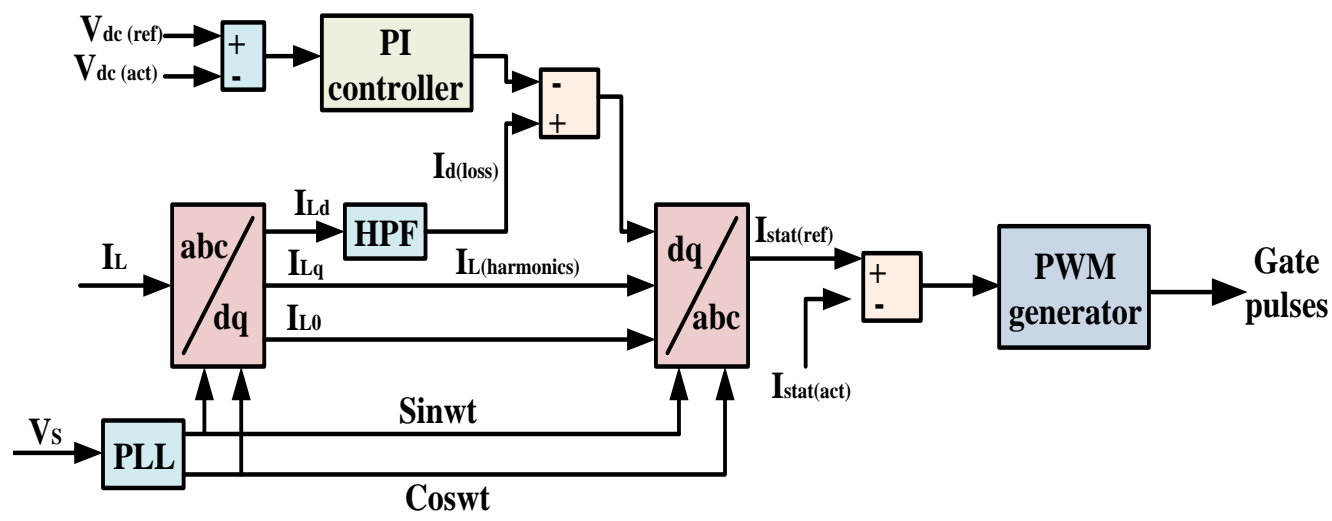

Figure 2. Block diagram for SRF theory based control

\subsection{Complete Block Diagram of SRF Controlled DVR}

The following Figure 3 shows the Control Block Diagram of the DVR. In this control, Source Voltage is sensed and is given as an input to the abc/dq transformation block. The same source voltage is given as an input to the PLL block, this PLL block gives the information of sin, cos. This is given as an input to the abc/dq block; with these two inputs this transformation block gives ILd, ILq, and ILo information. The quadrature and ILo axis is compared with 0 p.u. The error generated is given as an input to the PI controller, the PI controller output is again given as an input to dq/abc block and PLL information is also given as an input to dq/abc block. This block gives us the pulse information which is given as an input to PWM generator and from that gate pulses are generated, those gate pulses are for inverter. 


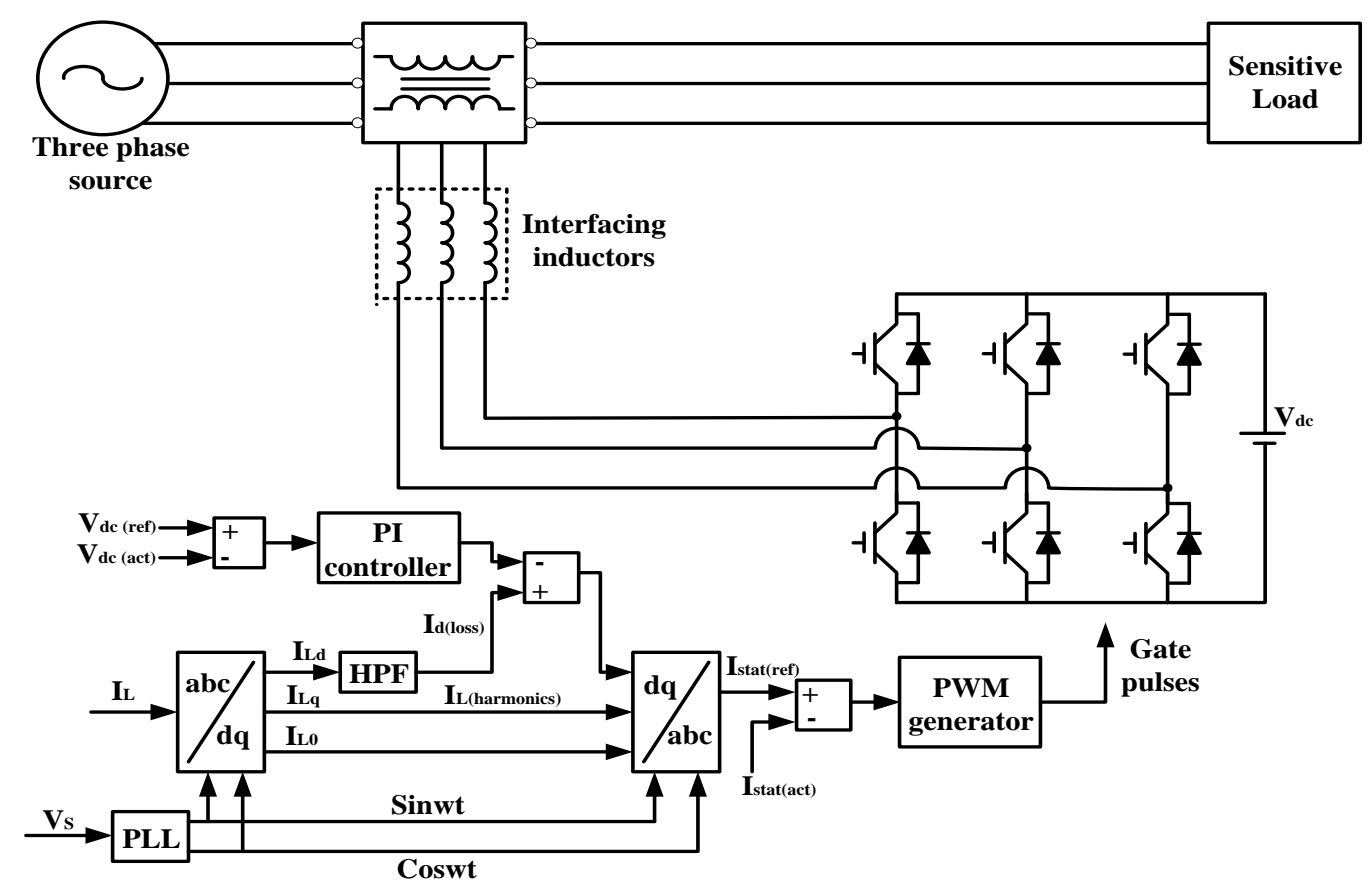

Figure 3. DVR with SRF theory

\section{TYPE OF CONTROL STRATEGIES IN DVR}

There are several techniques to implement and control philosophy of the DVR for power quality improvement in the distribution system. Most of the reported DVR systems are equipped with a control system that is configure to mitigate voltage sags/swells. Other DVR applications that include power flow control, reactive power compensation, as well as limited responses to power quality problems. The aim of the control scheme is to maintain constant voltage magnitude at the point where a sensitive load is connected under system disturbances [9]. The control system only measures the r.m.s voltage at the load point, i.e., no reactive power measurements are required. The control of DVR is very important and it involves detection of voltage sags (start, end and depth of the voltage sag) by appropriate detection algorithms which work in real time. The voltage sags can last from a few milliseconds to a few cycles, with typical depths ranging from 0.9 pu to $0.5 \mathrm{pu}$ of a $1 \mathrm{pu}$ nominal. Inverter is an important component of DVR. The performance of the DVR is directly affected to the control strategy of inverter. There have many studied been done by the researchers about the inverter control strategy for the DVR implementation [10], [11]. The inverter control strategy comprises of following two types of control as following:

\section{a. Linear Control and}

b. Non Linear Control

\subsection{Linear Control}

Linear control is considered as a common method of DVR control. Among the linear control been used in DVR are feed forward control, feedback control and composite control. Feed forward control is a simple method of DVR. The feed forward control technique does not sense the load voltage and it calculates the injected voltage based on the difference between the pre-sag and during-sag voltages.

The feedback control strategy measures the load and the difference between the voltage reference of the load and actual load voltage is injected voltage required [10], [11]. The feedback control methods based on state space systems, which can be set up closed-loop poles in order to make faster time response. Both the feed forward and the feedback control strategy may be implemented by scalar or vector control techniques. Composite control strategy is a control method with grid voltage feed forward and load side voltage feedback, which has the strengths of feed forward and feedback control strategy, so it can improve voltage compensation effect. If the feedback control in the composite control is designed to double-loop, it can improve system stability, system performance and the adaptability of dynamic load. The combination with feed forward control can improve the system dynamic response rate, shortening the time of compensation significantly. The control method with inductor current feedback and feed forward load current is designed without series transformers thus the size and cost of a DVR can be reduced. 


\subsection{Non- Linear Control}

Due to the usage of power semiconductor switches in the VSI, then the DVR is categorized as nonlinear device. In case of when the system is unstable, the model developed does not explicitly control target so all the linear control methods cannot work properly due to their limitation this paper.

\subsubsection{Artificial Neural Net Work (ANN) Control}

One of the non-linear methods of control is artificial neural network (ANN) control and it equipped with adaptive and self organization capacity. ANN control can monitor the non linear relationship based on input and output without the detail mathematical model. Normally ANN control can be classified into feed forward neural networks, feedback neural network, local approximation neural networks and fuzzy neural network based on structure [10], [11].

\subsubsection{Fuzzy Control}

Fuzzy logic (FL) control of DVR for voltage injection is also a controlling method. Its design philosophy deviates from all the previous methods by accommodating expert knowledge in controller design. It is derived from fuzzy set theory. FL controllers are an attractive choice when precise mathematical formulations are not possible. The advantages of this controller are capability to reduce the error and transient overshoot of pulse width modulation (PWM) [11].

\subsubsection{Space Vector Pwm (SVPWM) Control}

Space Vector PWM (SVPWM) control strategy used in AC motor variable speed drives by the Japanese scholars in the early 1980s. The main idea is to adopt a voltage inverter space vector of the switch to get quasi-circular rotating magnetic field instead of the original SPWM, so better performance of the exchange is gained in low switching frequency conditions. Besides the types of these controls, there is also available control for single phase sag detection methods used in DVR. Soft phase locked loop (SPLL), Mathematical Morphology theory based low-pass filter, Instantaneous Value Comparison Method are commonly used control for single phase voltage sag detection in the distribution system [10], [11].

\section{MATLAB/SIMULINK RESULTS}

\section{Case 1: DVR for Sag Condition}

Figure 4 shows the Source voltage, Injected voltage and Load voltages for Sag in power system. Sag is observed in source voltage during $0.1 \mathrm{sec}$ to $0.2 \mathrm{sec}$. DVR injects corresponding voltage compensating signals to power system and thus the load voltage is maintained with constant amplitude.

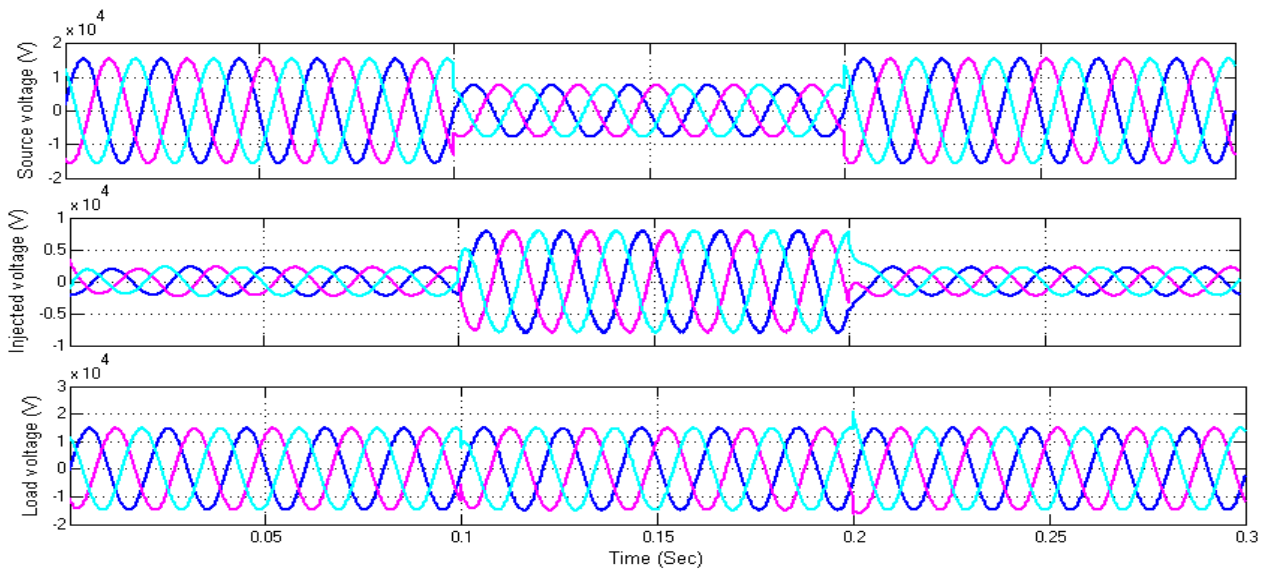

Figure 4. Source voltage, Injected voltage and Load voltages for Sag

\section{Case 2: DVR for Swell Condition}

Figure 5 shows the Source voltage, Injected voltage and Load voltages for Swell in power system. Swell is observed in source voltage during $0.1 \mathrm{sec}$ to $0.2 \mathrm{sec}$. DVR injects corresponding voltage compensating signals to power system and thus the load voltage is maintained with constant amplitude. 


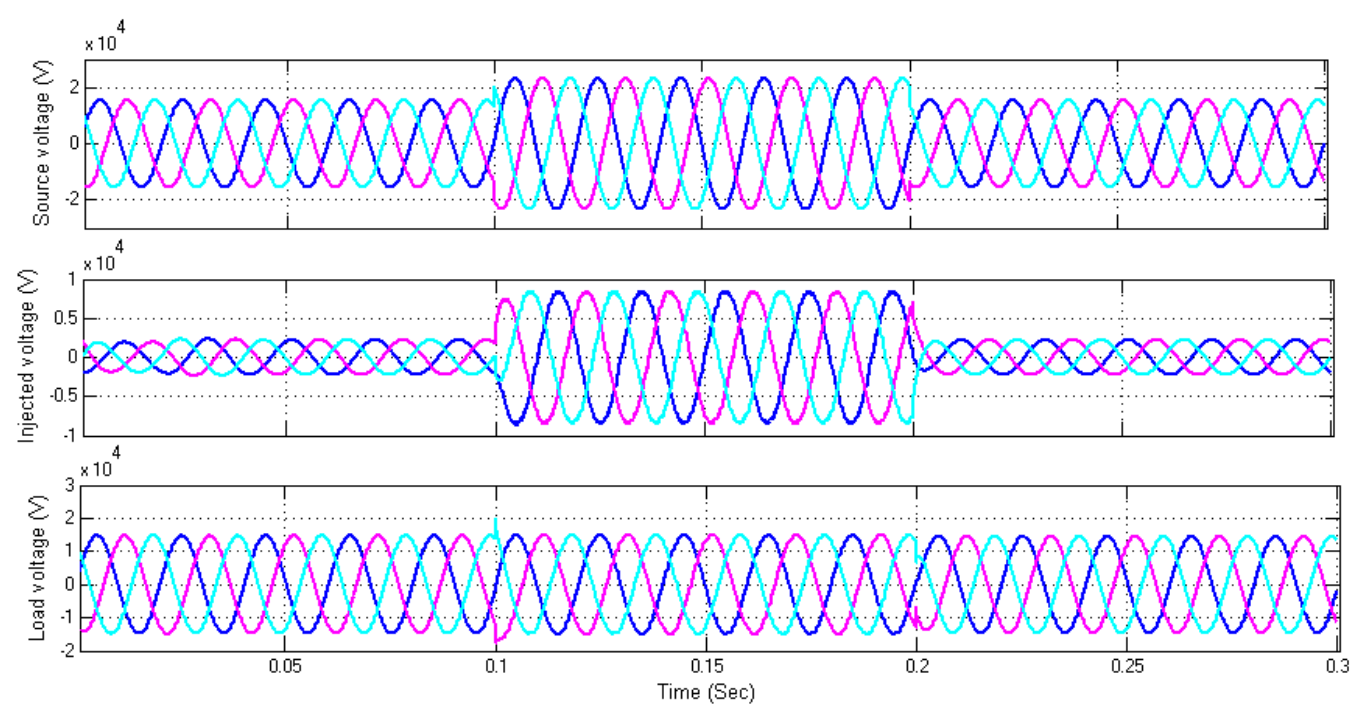

Figure 5. Source voltage, Injected voltage and Load voltage for Swell

\section{Case 3: DVR for Sag and Swell Conditions}

Figure 6 shows the Source voltage, Injected voltage and Load voltages for Sag and swell in power system. Sag is observed in source voltage during $0.1 \mathrm{sec}$ to $0.2 \mathrm{sec}$ and swell is observed during $0.25 \mathrm{sec}$ to $0.3 \mathrm{sec}$. DVR injects corresponding voltage compensating signals to power system and thus the load voltage is maintained with constant amplitude compensating sag and swell in power system.

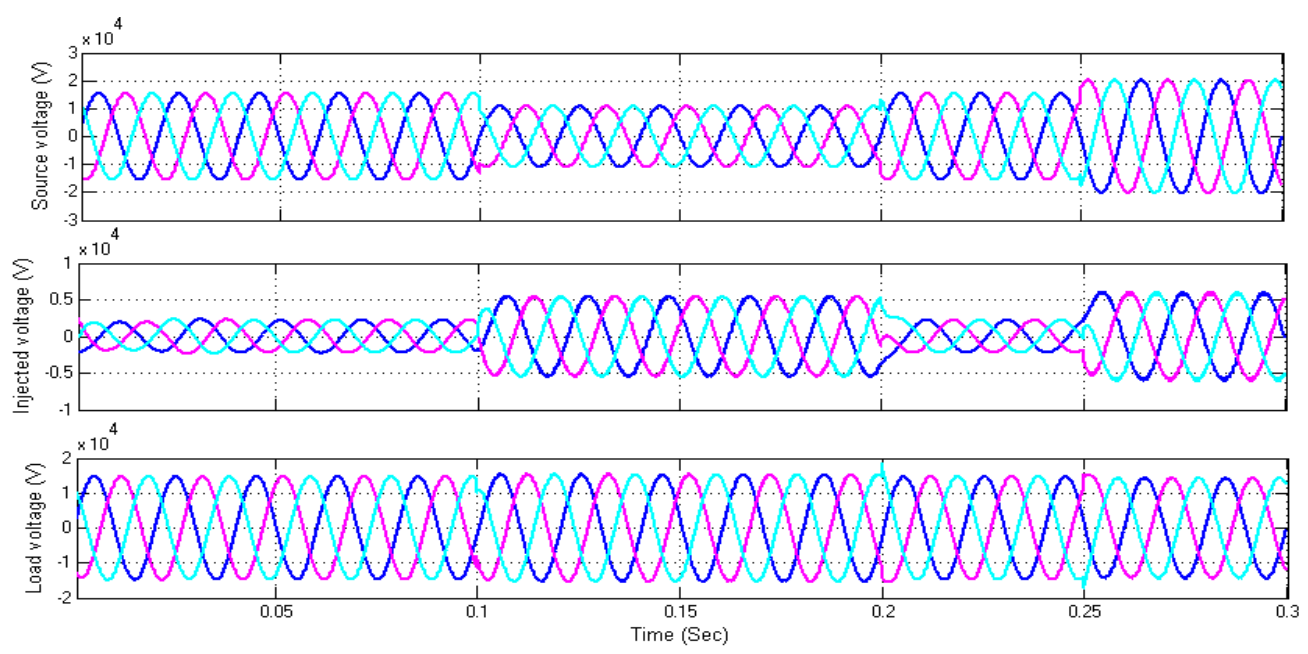

Figure 6. Source voltage, Injected voltage and Load voltage for Sag and Swell

\section{Case 4: DVR for Multi Sag Condition}

Figure 7 shows the Source voltage, Injected voltage and Load voltages for multi Sag condition in power system. Sag is observed in source voltage during $0.1 \mathrm{sec}$ to $0.2 \mathrm{sec}$ and also during $0.25 \mathrm{sec}$ to 0.35 sec. DVR injects corresponding voltage compensating signals to power system and thus the load voltage is maintained with constant amplitude compensating multi-sag condition. 


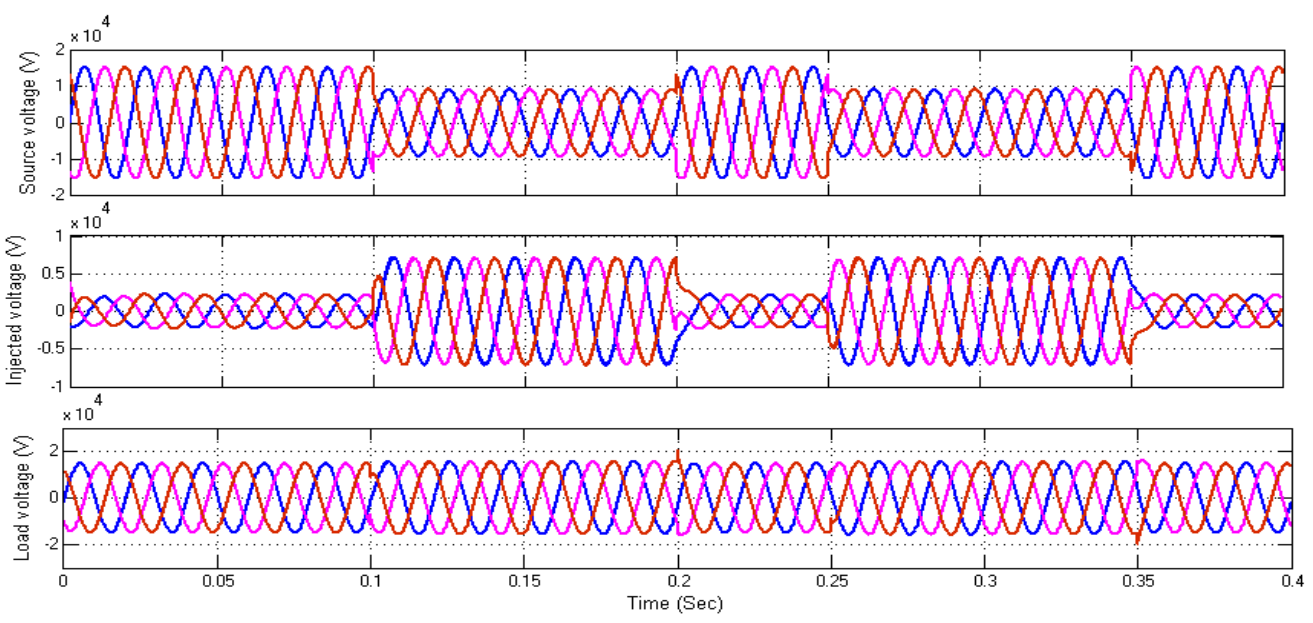

Figure 7. Source voltage, injected voltage and load voltage for multi Sag condition

\section{Case 5: DVR for Multi Swell Condition}

Figure 8 shows the Source voltage, Injected voltage and Load voltages for multi Swell condition in power system. Swell is observed in source voltage during $0.1 \mathrm{sec}$ to $0.2 \mathrm{sec}$ and also during $0.25 \mathrm{sec}$ to 0.35 sec. DVR injects corresponding voltage compensating signals to power system and thus the load voltage is maintained with constant amplitude compensating multi-swell condition.

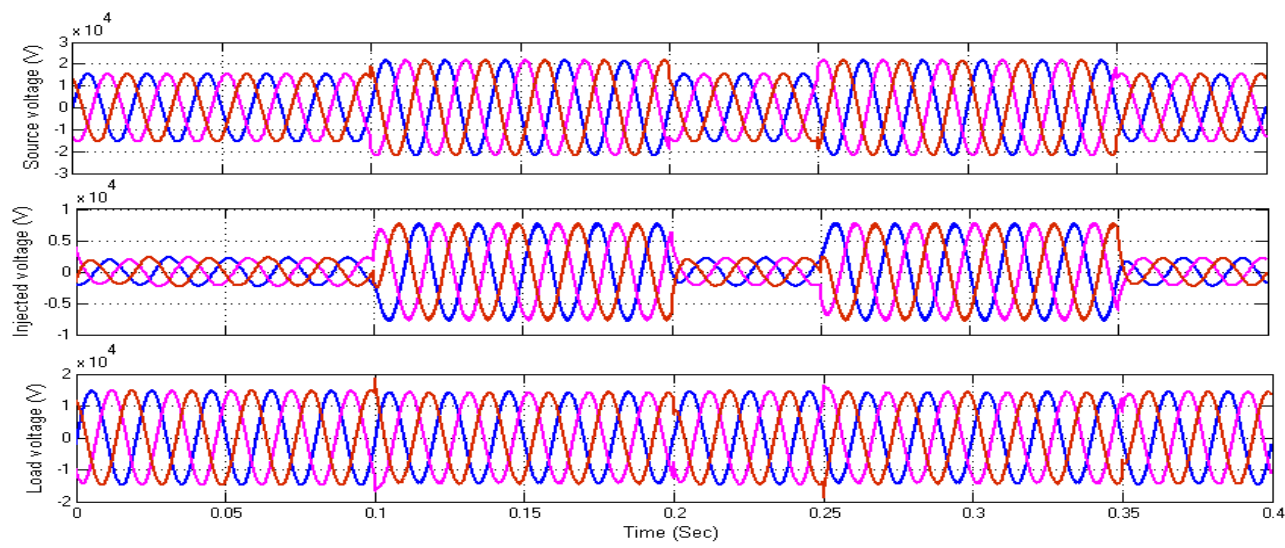

Figure 8. Source voltage, injected voltage and load voltage for multi Swell condition

\section{CONCLUSION}

In this paper a brief literature review is done on DVR configurations and its control strategies. By selecting any one of them we can provide solution to various power quality problems like voltage harmonics, voltage sag/swell compensation. To improve the performance of DVR, efforts needs to be made on energy savings, reduced parts and losses, minimum power injection, reduced rating, and selective harmonics mitigation. The above survey shows that the DVR is suitable for compensation of voltage sag and swell by the use of different controlling techniques. The linear control offer simpler implementation and require less computational efforts compared to other methods and therefore the most popular technique. The existing topologies, basic structure of DVR, operating modes, control strategies, compensation techniques and its control algorithm have been elaborated in detail. The main advantages of DVR are low cost, simpler implementation; require less computational efforts and its control is simple as compared to other methods. This study also gives useful knowledge for the researchers to develop a new design of DVR for voltage disturbances in electrical system. Therefore, DVR is considered to be an efficient solution due to its low cost, small size, and fast dynamic response. The simulation results show clearly the performance of a DVR in mitigating voltage sags and swells. 


\section{REFERENCES}

[1] Dong-Jun Won, Seon-Ju Ahn, 11-Yop Chung, Joong-Moon Kim and Seung-I1 Moon, "A New Definition of Voltage Sag Duration Considering The Voltage Tolerance Curve" Bologna Power Tech Conference, IEEE 2003, June 23-26, Bologpa, Italy.

[2] M.R. Banaei, S.H. Hosseini, G.B. Gharehpetian, "Inter-Line Dynamic Voltage Restorer Control Using A Novel Optimum Energy Consumption Strategy" Volume 14, Issue 7, Pages 989-999, October 2006.

[3] A. Sannino, G. Michelle and M. Bollen, "Overview of Voltage Sag Mitigation” IEEE Power Engineering Society 2000 Winter Meeting, January 2000, Vol. 4, pp.23-27.

[4] Trevor L. Grant and Deepak M. Divan, "Power Quality Solutions to Mitigate the Impact of Voltage Sags in Manufacturing Facilities", AEE-WEEC 2002.

[5] D.K. Tanti, M.K. Verma, Brijesh Singh, O.N. Mehrotra, "Optimal Placement of Custom Power Devices in Power System Network to Mitigate Voltage Sag under Faults," International Journal of Power Electronics and Drive Systems (IJPEDS), Vol 2 No 3, 2012 pages 267-276.

[6] Haniyeh Marefatjou, Mohammad Sarvi, "Compensation Of Single-Phase and Three-Phase Voltage Sag and Swell Using Dynamic Voltage Restorer”, International Journal of Applied Power Engineering (IJAPE), 2012, Vol 1 No 3, pages $129-144$.

[7] Mohammad Sarvi, Haniyeh Marefatjou, "Compensation of Voltage Single-Phase SAG and SWELL Using Dynamic Voltage Restorer and Difference Per-Unit Value Method", International Journal of Electrical and Computer Engineering (IJECE), 2013, Vol 3 No 1, pages 83-92.

[8] C.S.Chang, Y.S. ho and P.C. Loh, "Voltage Quality Enhancement with Power Electronics Based Devices" IEEE 2000.

[9] C. Benachaiba and B. Ferdi, "Power Quality Improvement Using DVR", American Journal of Applied Sciences, March, 2009.

[10] G. Ramya, V. Ganapathy, P. Suresh, "Power Quality Improvement Using Multi-Level Inverter Based DVR and DSTATCOM Using Neuro-Fuzzy Controller," International journal of power electronics and drive systems (IJPEDS), March 2017, Vol 8, No 1:, pp 316-324.

[11] Brahim Ferdi, Samira Dib, Brahim Berbaoui, Rachid Dehini, "Design and Simulation of Dynamic Voltage Restorer Based on Fuzzy Controller Optimized by ANFIS," International journal of power electronics and drive systems (IJPEDS), June 2014, Vol 4, No 2:, pp 212-222.

[12] D.K. Tanti, M.K. Verma, Brijesh Singh, O.N. Mehrotra, "Optimal Placement of Custom Power Devices in Power System Network to Mitigate Voltage Sag under Faults," International journal of power electronics and drive systems (IJPEDS), September 2012, Vol 2, No 3:, pp 267-276.

[13] Ezoji, A.Sheikholeslami, M. Tabasi and M.M. Saeednia“Simulation of Dynamic Voltage Restorer Using Hysteresis Voltage Control” European Journal of Scientific Research ISSN 1450-216X Vol.27 2009, No.1 pp.152-166. 